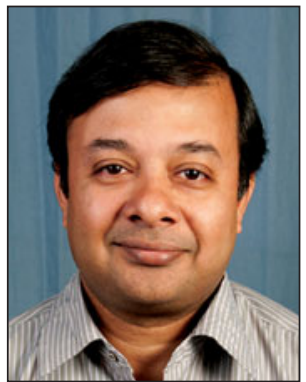

Amit Bandyopadhyay

Guest Editor for this issue of MRS Bulletin

School of Mechanical and Materials

Engineering, Washington State

University, USA; tel. 509-335-4862; and

email amitband@wsu.edu.

Bandyopadhyay is a Herman and Brita Lindholm Endowed Chair Professor in the School of Mechanical and Materials Engineering at Washington State University. His research is focused on additive manufacturing of hard materials toward structural and biomedica applications. He has published over 250 technical articles, holds 10 US patents, and has edited eight books. He is a Fellow of the National Academy of Inventors, American Association for the Advancement of Science, The American Ceramic Society, American Society for Materials, and American Institute for Medical and Biological Engineering.

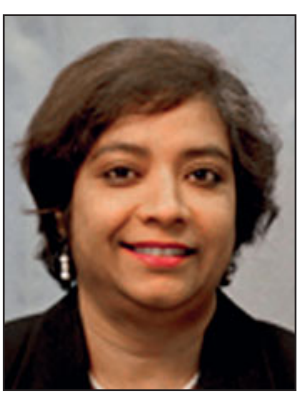

Susmita Bose

Guest Editor for this issue of MRS Bulletin

School of Mechanical and Materials

Engineering, Washington State University,

USA; tel. 509-335-7461; and

email sbose@wsu.edu.

Bose is a Herman and Brita Lindholm Endowed Chair Professor of the School of Mechanical and Materials Engineering at Washington State University. Her research interests are at the interface of chemistry, materials science, and biology involving orthopedic implants, 3D printing, and drug delivery. She received the National Science Foundation Presidential CAREER Award as well as Professiona Achievement in Ceramic Engineering and Fulrath Awards from The American Ceramic Society (ACerS). She has published over 200 papers. She is a Kavl Fellow of the National Academy of Sciences and a Fellow of the American Institute for Medical and Biological Engineering and the ACerS.

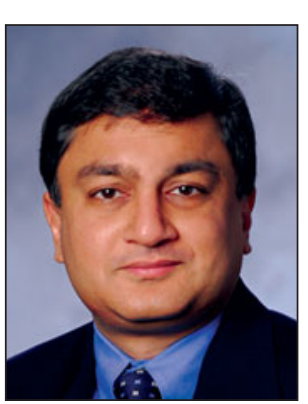

\section{Suman Das}

Guest Editor for this issue of MRS Bulletin

Direct Digital Manufacturing Laboratory, Woodruff School of Mechanical Engineering, and School of Materials Science and Engineering, Georgia Institute of Technology, USA; tel. 404-385-6027; and emailsumandas@gatech.edu.

Das is the Morris M. Bryan Jr. Chair in Mechanical Engineering for Advanced Manufacturing Systems, professor of mechanical engineering and materials science and engineering, and director of Georgia Tech's Direct Digital Manufacturing Laboratory. He is a program faculty member at the Parker H. Petit Institute for Bioengineering and Bioscience and also at the Interdisciplinary Bioengineering Graduate Program. Das is the founder and CEO of DDM systems, an additive manufacturing startup. He received his $\mathrm{PhD}$ degree in 1998 from The University of Texas at Austin and was an associate professor of mechanical engineering at the University of Michigan-Ann Arbor, prior to joining Georgia Tech in 2007.

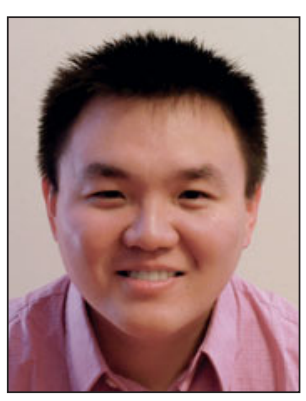

Hanying Bai

Department of Orthopedic Surgery,

Columbia University, USA

Bai has been a research fellow at Columbia University since 2011. He earned his $\mathrm{PhD}$ degree in chemistry and biochemistry from City University of New York (CUNY). His research interests focus on two fields: nanomaterial/nanotechnology with an application in biomedical fields, and 3D printing technology with an application in orthopedics and dental surgeries. He received a Sponsored Dissertation Fellowship Award from CUNY in 2009.

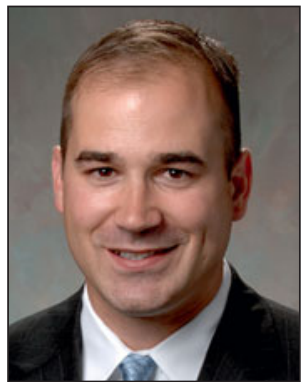

Matthew L. Becker

Department of Polymer Science;

The University of Akron, USA

tel. 330-972-2834; and

email becker@uakron.edu.

Becker is a professor of polymer science and biomedical engineering at The University of Akron and the director of the Akron Functional Materials Center. He received his $\mathrm{PhD}$ degree in organic chemistry in 2003 from Washington University in St. Louis on a National Institutes of Health Chemistry-Biology Interface training fellowship with Karen L. Wooley. From 2003 to 2009, he was a National Research Council postdoctoral fellow and then project leader in the Polymers Division at the National Institute of Standards and Technology. His research group focuses on synthesizing macromolecular materials for molecular sensing and regenerative medicine applications.

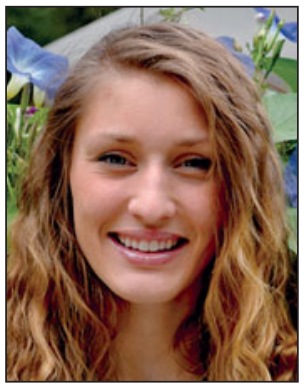

\section{Erin P. Childers}

Department of Polymer Science,

The University of Akron, USA;

tel. 330-671-0013; and

emailepc7@zips.uakron.edu.

Childers is a fourth-year $\mathrm{PhD}$ candidate in the Department of Polymer Science at The University of Akron. She has been awarded a National Science Foundation fellowship while working under Matthew L. Becker. Her current research focuses on poly(ester urea)s, degradable biomaterials, 3D printing, protein adsorption characteristics, platelet-rich plasma, poly(propylene fumarate), poly(ethylene glycol)/3D-peptide gradient, and 2D-surface methyl gradient effects on arthritic chondrocytes. She is the author of three journal papers in preparation.

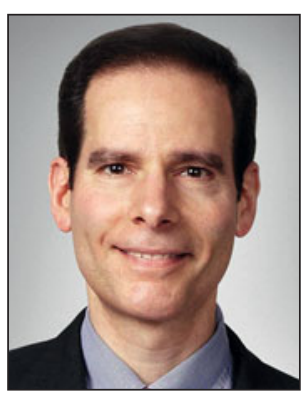

David Dean

Department of Plastic Surgery, The Ohio State University, USA; tel. 614-688-9044; and email david.dean@osumc.edu.

Dean is an associate professor of Plastic Surgery and a member of the Center for Regenerative Medicine and Cell-Based Therapies at The Ohio State University. He directs the Osteo Engineering Laboratory, which focuses on bone tissue engineering and musculoskeletal regenerative medicine. His current research focuses on computer-aided implant design and biomechanical modeling, additive manufacturing, bone progenitor cells, growth factors, and bioreactor technologies. He has authore 58 journal papers, 30 proceedings papers, and 14 book chapters, and is an inventor on 14 issued or pending patents.

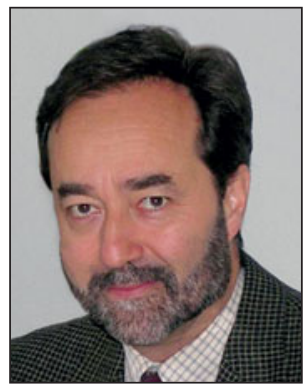

Lorenzo Fedrizzi

Chemistry Physics and Environment Department, University of Udine, Italy; tel. +39 0432558 838; and email lorenzo.fedrizzi@uniud.it.

Fedrizzi is the head of the Chemical Science and Technology Department since 2009 and the Department of Chemistry Physics and Environment since 2011 at the University of Udine. He is a full professor of materials science and technology since 2003 and is the director of the Laboratory of Metallurgy, Surface Technologies, and Advanced Materials at Friuli Innovazione since 2006. He is member and president of numerous committees, editorial boards, and master schools in several countries. He has published several books and papers mainly related to coating technologies, corrosion, and metal alloys preparation and characterization. 


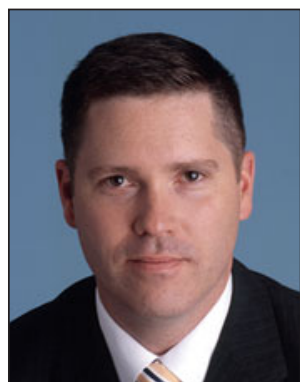

\section{John P. Fisher}

Fischell Department of Bioengineering,

University of Maryland, USA;

tel. 301-405-7475; and

email jpfisher@umd.edu.

Fisher is the Fischell Family Distinguished Professor and Associate Chair for Graduate Studies in the Fischell Department of Bioengineering at the University of Maryland. He is the director of the Tissue Engineering and Biomaterials Laboratory and investigates biomaterials, stem cells, and bioreactors for the regeneration of lost tissues, particularly bone, cartilage, vasculature, and skeletal muscle. He has been the research advisor to $11 \mathrm{PhD}$ students, three MS students, and over 50 undergraduate researchers. In 2012, he was elected Fellow of the American Institute for Medical and Biological Engineering. He is currently the Editor-in-Chief of the journal Tissue Engineering, Part B: Reviews.

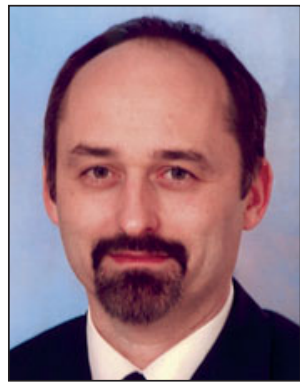

\section{Uwe Gbureck}

Department for Functional Materials in

Medicine and Dentistry, University of

Würzburg, Germany; tel. +49 931 20173550; and email uwe.gbureck@fmz.uni-wuerzburg.de.

Gbureck is a professor in the Department for Functional Materials in Medicine and Dentistry at the University of Würzburg. He earned a $\mathrm{PhD}$ degree in chemistry from the University of Würzburg in 1999. His research interests include the chemistry and material properties of mineral biocements based on calcium and magnesium phosphate chemistry, the use of such cements in rapid prototyping applications, as well as drug delivery systems based on inorganic structured materials.

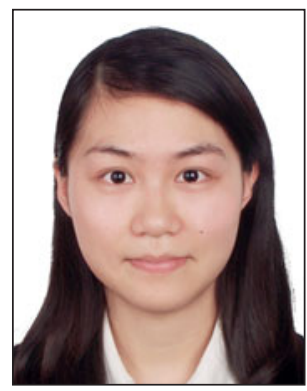

\section{Ling He}

College of Dental Medicine, Columbia University, USA; email Ih2685@columbia.edu.

$\mathrm{He}$ is a PhD student at Columbia University, where her thesis research focuses on biomaterial scaffolds and signaling transduction of stem/progenitor cells. She received a dental degree from Sun Yat-sen University, China, in 2012.

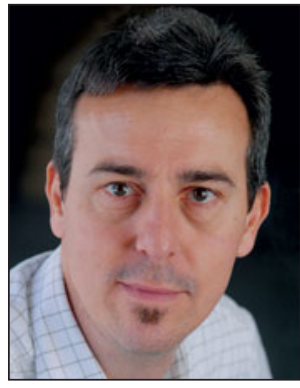

Dietmar Hutmacher

Institute of Health and Biomedical Innovation, Queensland University of Technology,

Australia; tel. +61 73138 6077; and email dietmar.hutmacher@qut.edu.au. Hutmacher is the QUT Chair in Regenerative Medicine at the Queensland University of Technology's Institute of Health and Biomedical Innovation and a Hans Fischer Senior Fellow at the Institute of Advanced Studies at the Technical University of Munich. He earned an MBA degree at the University of Reading's Henley Business School and a PhD degree at the National University of Singapore. He is a multidisciplinary biomedical engineer, educator, inventor, and creator of new intellectual property opportunities, one of a few to support a bone-tissue engineering concept along the entire course from the laboratory to clinical application involving in vitro, in vivo, preclinical large animal studies, and clinical trials. He has published more than 240 journal articles, 45 book chapters, more than 450 conference abstracts, and edited 10 books.

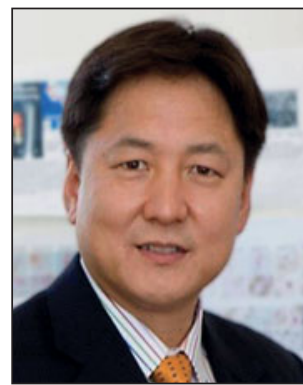

Francis Y. Lee

Department of Orthopedic Surgery,

Columbia University Medical Center

New York-Presbyterian Hospital, USA.

Lee is a professor and an orthopedic surgeon at the Columbia University Medical Center. He has expertise in bone and soft tissue tumors, metastatic bone cancers, and pediatric orthopedic surgery. He is one of a few orthopedic surgeons with National Institutes of Health R01 research grants and conducts high-impact translational research in the field of bone regeneration. His recent research has focused on establishing a new paradigm of tissue engineering that utilizes 3D-printed bone segments that accurately match human bone size and shape.

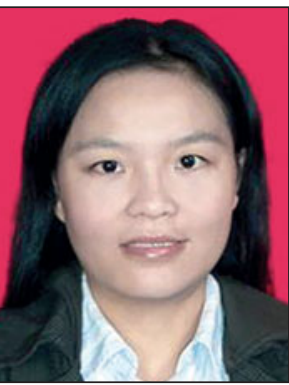

Juan Li

Center for Craniofacial Regeneration, Columbia University; and Sichuan University, China $\mathrm{Li}$ is a visiting scientist in the Center for Craniofacial Regeneration at Columbia University and also an associate professor at Sichuan University, China. She obtained both dental specialty training and a PhD degree from Sichuan University, followed by a scholarship in support of her research at Columbia. Her research interests include biomaterial scaffolds and stem cell biology in relation to tissue engineering. She has published over a dozen peer-reviewed papers in the field of tissue engineering.

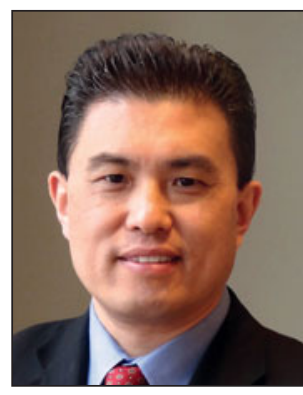

Jeremy J. Mao

College of Dental Medicine, Columbia University, USA; tel. 212-305-4475 and emailjm2654@columbia.edu.

Mao is a professor and Edwin Robinson Endowed Chair at Columbia University, recruited in 2006 to build the interface between stem cell biology and tissue engineering. His research team has been at Columbia for the past seven years. He has authored over 260 publications and two books. His research has led to over 70 patents and the establishment of two biotechnology companies. He is a consultant to funding agencies in the United States (NIH, NSF, DARPA) and over 18 other countries. His awards include the Yasuda Award, IADR Distinguished Scientist Isaac Schour Memorial Award, and Spenadel Award.

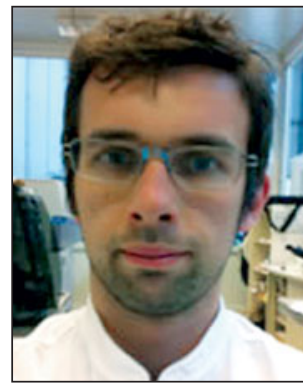

\section{Elia Marin}

Chemistry, Physics and Ambient

Department, University of Udine, Italy; tel. +390432 629 973; and email elia.marin@uniud.it.

Marin studied mechanical engineering at the University of Udine. He received his master's degree in 2007, with a thesis on trabecular titanium structures obtained by electron beam melting, followed with a metallurgical engineering master's degree at the University of Udine in 2008. In 2012, he obtained his PhD degree in metallurgical engineering at the University of Padua, Italy, with a thesis on the protection of metallic prosthetic implants in biological environments and characterization of 3D structures for implant/bone interactions. 


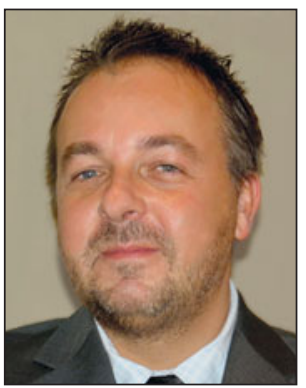

Claus Moseke

Department for Functional Materials

in Medicine and Dentistry, University

of Würzburg, Germany; email claus.

moseke@fmz.uni-wuerzburg.de.

Moseke is a senior researcher in the Department for Functional Materials in Medicine and Dentistry at the University of Würzburg. He received his PhD degree at the Institute for Nuclear Physics of the University of Münster, Germany. His work focuses on biointerface engineering and characterization as well as the investigation of metal-substituted ceramics for biomedical applications.

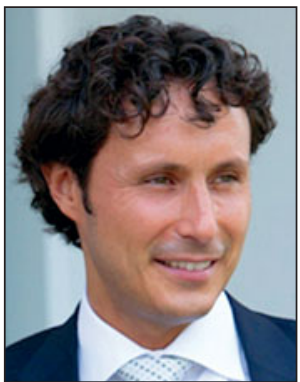

\section{Michele Pressacco}

Lima Corporate, Italy; tel. +39 0432 945511; and email michele.pressacco@limacorporate.com. Pressacco is the product development director at Lima Corporate, where he is responsible for the development of hip, knee, extremities, and fixation products, and all developments related to additive manufacturing and custom-made products. He has been involved in the additive manufacturing industry since 2000 and has written numerous related articles and presented at various symposia. He has conducted research on the development of titanium alloys and processing techniques for enhanced biocompatibility.

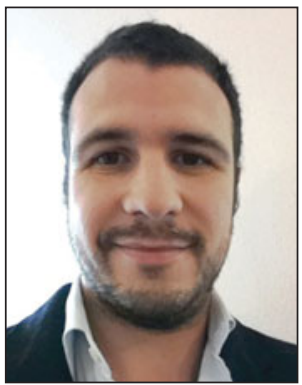

\section{Marco Regis}

Lima Corporate, Italy; tel. +39 0432945 667;

and email marco.regis@limacorporate.com.

Regis is in charge of the additive manufacturing

$R \& D$ department at Lima Corporate, where he focuses on the development of new materials and products for orthopedics related to these technologies. After earning his MS degree in materials science and engineering at the University of Trieste, Italy, he joined Lima Corporate in 2008. He is completing his PhD degree in chemistry and materials science at the University of Torino, Italy.

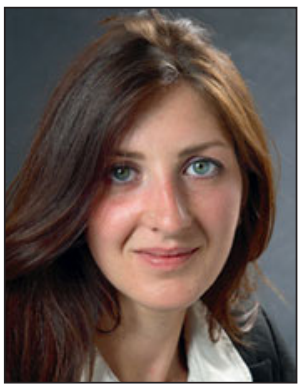

\section{Elke Vorndran}

Department for Functional Materials in Medicine and Dentistry, University of Würzburg, Germany; email elke.vorndran@fmz.uni-wuerzburg.de.

Vorndran is a postdoctoral researcher in the Department for Functional Materials in Medicine and Dentistry at the University of Würzburg. She received her $\mathrm{PhD}$ degree in physics in 2011 under the supervision of Uwe Gbureck. Her work involves the 3D powder printing of ceramic materials for medical applications and the use of bioceramics as a drug delivery system. In 2012, she received the Sponsorship Award for an excellent dissertation from the German Biomaterial Society.

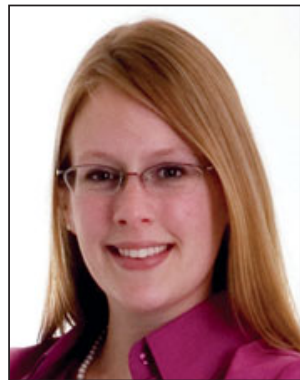

Martha 0. Wang

Fischell Department of Bioengineering,

University of Maryland, USA

tel. 410-608-1167; and

email marthaeowang@gmail.com.

Wang is a consultant with JWE, LLC, and an instructor at the University of Maryland. She received her BS degree in chemical engineering and biomedical engineering from Carnegie Mellon University in 2004 and received her PhD degree in bioengineering from the University of Maryland, College Park, in 2014. Her areas of research include characterizing 3D printing using micro-computed tomography, evaluating the cytotoxicity of absorbable polymers, tissue engineering, stem cells, and bioreactors.

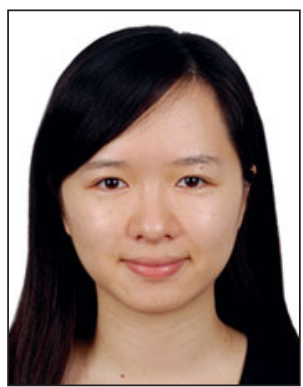

\section{Chen Zhou}

College of Dental Medicine, Columbia University, USA; email cz2329@columbia.edu.

Zhou is a $\mathrm{PhD}$ degree candidate pursuing thesis research at Columbia University with a particular interest in biomaterials and tissue engineering. She graduated from Sun Yat-sen University, China. Her research interests focus on the interface of biomaterial scaffolds and stem cells in tissue regeneration.

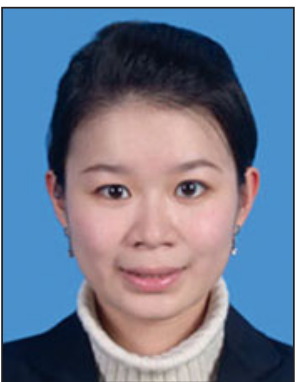

Yue Zhou

College of Dental Medicine, Columbia

University, USA; email yz2643@columbia.edu. Following a three-year clinical practice, Zhou pursued a $\mathrm{PhD}$ degree in biomaterials and stem cell biology in a joint program between West China School of Stomatology, Sichuan University, and Columbia University. She graduated with a dental degree from the School of Stomatology at Tongji University, China, in 2008. Her current research focuses on biomaterial polymers and novel genes that regulate tooth regeneration and osteoarthritis
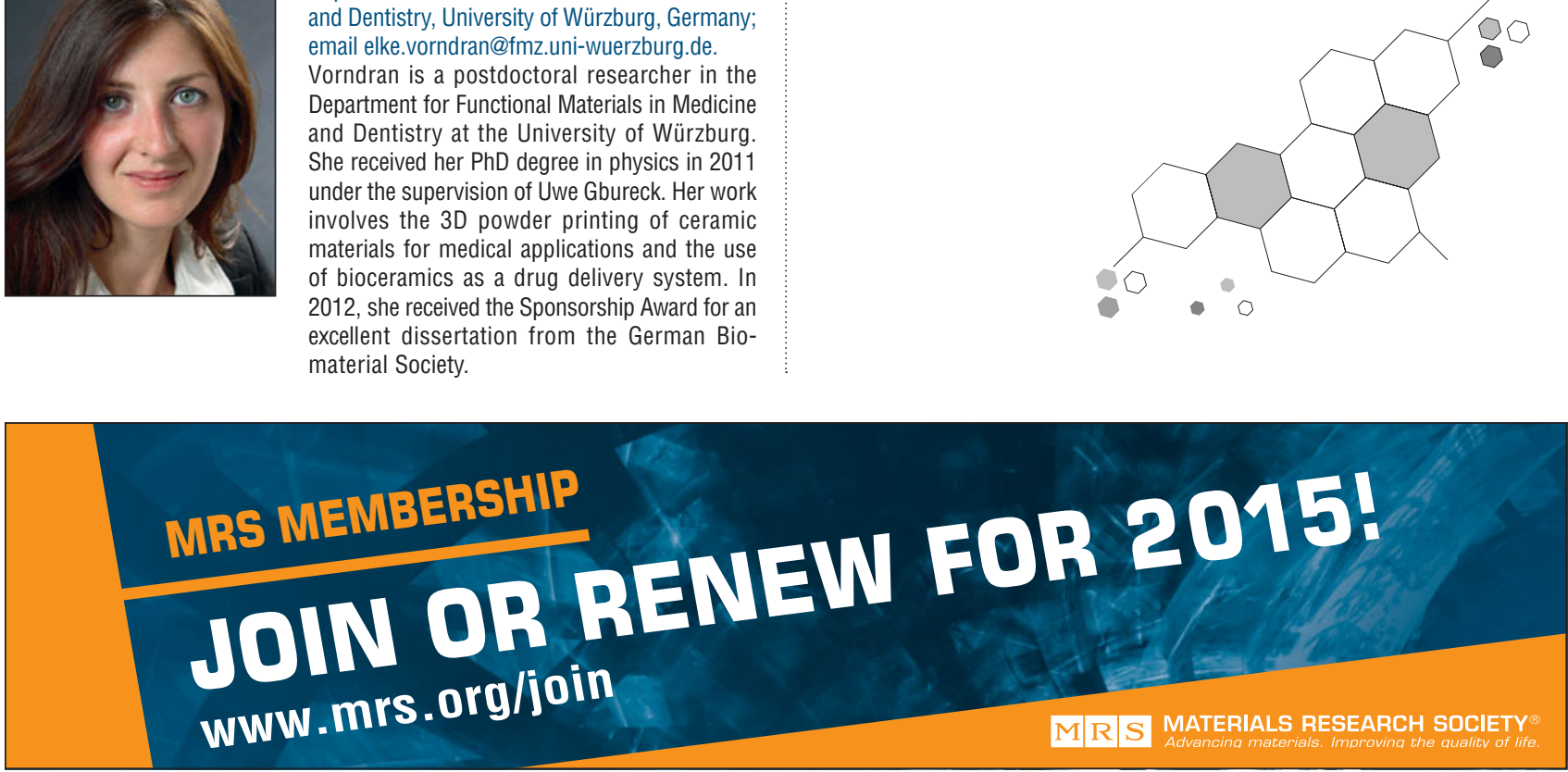